\section{Second-look ultrasonography for MRI-detected suspicious breast lesions in patients with breast cancer}

\author{
Min Ji Hong ${ }^{1}$, Joo Hee Cha ${ }^{1}$, Hak Hee Kim ${ }^{1}$, Hee Jung Shin ${ }^{1}$, Eun Young Chae', \\ Ji Eun Shin ${ }^{1,2}$, Woo Jung Choi ${ }^{1}$ \\ 'Department of Radiology and Research Institute of Radiology, Asan Medical Center, \\ University of Ulsan College of Medicine, Seoul; ' $D$ Department of Radiology, Gangnam CHA \\ Hospital, CHA University College of Medicine, Seoul, Korea
}

Purpose: The purpose of this study is to evaluate the use of second-look ultrasonography (US) for investigating additional suspicious lesions detected on preoperative staging magnetic resonance imaging (MRI) for breast cancer.

Methods: Between September 2008 and August 2010, 1,970 breast MRIs were performed at our medical institution for the evaluation of breast cancer before surgery. Second-look US was recommended for 135 patients with 149 suspicious lesions, following the MRI interpretation, and 108 patients with 121 lesions were included in this study. The detection rate on second-look US, according to the lesion type, diameter, and histopathological outcome, was analyzed.

Results: Of the 121 lesions considered in this study, 97 (80.2\%) were diagnosed on MRI as masses and 24 (19.8\%) as non-mass-like lesions; 105 lesions (86.8\%) were correlated and 16 $(13.2 \%)$ were not correlated with the findings of second-look US. Of the 105 correlated lesions, $29(27.6 \%)$ were proven to be malignant and $76(72.4 \%)$ were benign. Although a greater number of large malignant lesions were correlated on second-look US than small benign lesions, there was no statistically significant difference according to lesion diameter or type, as seen on MRI or pathology.

Conclusion: We have concluded that second-look US is a useful diagnostic tool for lesions incidentally detected on breast MRI, as in this study, it could identify $86.8 \%$ of the MRI-detected breast lesions.

Keywords: Breast; Magnetic resonance imaging; Ultrasonography

\section{Introduction}

Magnetic resonance imaging (MRI) can reveal clinically and mammographically occult breast cancer, and its sensitivity is reported to range from $94 \%$ to $100 \%$ for invasive carcinoma and from $40 \%$ to $100 \%$ for ductal carcinoma in situ (DCIS) [1-3]. However, the primary limitations of this modality include a large number of false-positive findings [4] and the difficulty of managing incidentally detected lesions seen on MRI [5]. Because of the limited specificity of the imaging modality, tissue

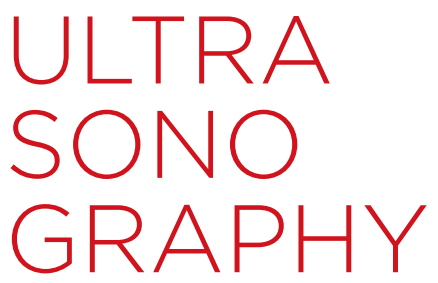

ORIGINAL ARTICLE

http://dx.doi.org/10.14366/usg. 14046 pISSN: 2288-5919 • elSSN: 2288-5943 Ultrasonography 2015;34:125-132

Received: October 15, 2014

Revised: December 16, 2014

Accepted: December 18, 2014

Correspondence to:

Joo Hee Cha, MD, Department of Radiology and Research Institute of Radiology, Asan Medical Center, University of Ulsan College of Medicine, 88 Olympic-ro 43-gil, Songpa-gu, Seoul 138-736, Korea

Tel. +82-2-3010-5995

Fax. $+82-2-476-0090$

E-mail: jhcha@amc.seoul.kr

This is an Open Access article distributed under the terms of the Creative Commons Attribution NonCommercial License (http://creativecommons.org/ licenses/by-nc/3.0/) which permits unrestricted noncommercial use, distribution, and reproduction in any medium, provided the original work is properly cited.

Copyright (C) 2015 Korean Society of Ultrasound in Medicine (KSUM)

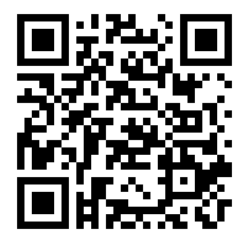

How to cite this article:

Hong MJ, Cha JH, Kim HH, Shin HJ, Chae EY, Shin JE, et al. Second-look ultrasonography for MRI-detected suspicious breast lesions in patients with breast cancer. Ultrasonography. 2015 Apr;34(2):125-132. 
sampling is necessary for a definite diagnosis of MRI-detected breast lesions [6,7]. MRI-guided percutaneous biopsy and MRI-guided needle localization can be performed using commercial equipment; however, these methods are not yet widely available and easily accessible due to the high cost and extensive time needed, and the use of an MRI magnet [6-10].

In general, ultrasonography (US)-guided biopsy is preferable to MRI-guided biopsy, whenever possible, as this method is less expensive, less uncomfortable, and more practical for the patient [11]. US may also be helpful in the further differentiation of a target lesion when its findings are correlated with the MRI findings [11]. The purpose of the present study is to investigate the efficacy and importance of second-look US in evaluating additional suspicious lesions detected on preoperative staging MRI of breast cancer.

\section{Materials and Methods}

This retrospective study was approved by our hospital's Institutional Review Board, and the requirement for informed consent was waived. However, written informed consent was obtained from all patients before fine-needle aspiration or core-needle biopsy (CNB).

\section{Breast MRI Technique}

Dynamic contrast-enhanced MRI was performed using a 1.5-T scanner (Magnetom Avanto, Siemens Medical Solutions, Erlangen, Germany) equipped with a bilateral, 16-channel breast array coil (Siemens Medical Solutions). The standard MRI protocol included the following pulse sequences: (1) axial two-dimensional (2D) T2-weighted short tau inversion recovery turbo spin-echo pulse sequence (repetition time [TR]/echo time [TE]/time interval, 6,700/74/150 msec; field of view [FOV], $300 \mathrm{~mm} \times 300 \mathrm{~mm}$; matrix, $448 \times 448$; slice thickness, $5 \mathrm{~mm}$ ), (2) precontrast- and postcontrastenhanced fat-saturated axial three-dimensional (3D) T1-weighted fast low-angle shot volume-interpolated breath-hold examination pulse sequences (TR/TE, 5.2/2.4 msec; FOV, $340 \mathrm{~mm} \times 340 \mathrm{~mm}$; matrix, 384×384; slice thickness, $0.9 \mathrm{~mm}$ ), and (3) axial 3D delayed contrast-enhanced turbo spin-echo pulse sequence (TR/TE, 767/12 msec; FOV, $350 \mathrm{~mm} \times 350 \mathrm{~mm}$; matrix, 768×768; slice thickness, $5 \mathrm{~mm}$ ) for the evaluation of the supraclavicular and axillary lymph nodes. Six dynamic sequences were performed before and after contrast injection. The contrast medium $(0.2 \mathrm{~mL} / \mathrm{kg}$ body weight; Magnevist, Schering, Berlin, Germany) was injected using an MRIcompatible power injector (Spectris, Medrad, Pittsburgh, PA, USA) at a flow rate of $1 \mathrm{~mL} / \mathrm{sec}$ followed by a $20-\mathrm{mL}$ saline flush. Postprocessing manipulation included standard subtraction, reverse subtraction, and maximum-intensity projection images.

\section{MRI Interpretation}

Between September 2008 and August 2010, 2,065 breast MRI examinations were performed at our medical institution. Among them, 1,970 breast MRIs were performed to evaluate the preoperative staging or the postexcisional state of histologically confirmed breast cancer or for the workup of metastatic axillary lymphadenopathy.

During the period from September 2008 to August 2010, all the MRI scans taken at our institution were interpreted by a radiologist with 18 years of clinical experience in breast radiology. These MRI scans were interpreted using the information of the imaging findings of mammography and breast US as both of these studies are usually performed before MRI at our medical institution. Based on a previous report, we classified the MRI findings of the 121 lesions considered in this study in terms of morphology (mass or non-masslike enhancement), diameter, and final assessments according to the Breast Imaging Reporting and Data System (BI-RADS) lexicon for MRI [12].

Second-look US was recommended for 149 incidental suspicious lesions detected on MRI in 135 patients. These lesions were occult on both mammography and the initial US and were predicted to induce a significant change in patient management; they included masses with irregular shape, irregular and spiculated margin, and marked enhancement, and non-mass-like enhancements with ductal and clumped enhancement patterns [13]. Second-look US was not recommended for focus, benign, or benign-appearing lesions such as intramammary lymph nodes, fat-containing lesions, fibroadenomas, cysts, and masses with an oval or round shape with a circumscribed margin and homogeneous internal enhancement, as seen on MRI [14]. In the end, 108 patients with 121 lesions were included in the present study, after excluding the patients in whom US was performed before MRI, although second-look US was not performed before their surgery.

\section{Second-Look US}

Second-look US was performed by one of our five radiologists with 3-9 years of clinical experience. US was performed using the IU22 system (Philips Medical Systems, Bothell, WA, USA), which was equipped with a 50-mm array transducer with a bandwidth of 5-12 MHz. US scanning was performed with special attention paid to the anatomical area of the detected lesion and by using MRI images as a guide. The MRI study results should be thoroughly reviewed before performing second-look US. To determine the location of an enhancing lesion on MRI, we divided the breast into four quadrants using both the axial and the sagittal plane passing through a nipple as a reference point. The lesion diameter, shape, and type are also helpful in detecting and correlating lesions seen on MRI with those 
Table 1. Summary of second-look US correlated and non-correlated lesions among $121 \mathrm{MRI}$-detected suspicious lesions in 108 patients

\begin{tabular}{lccc}
\hline \multicolumn{1}{c}{ Variable } & Correlated lesions & Non-correlated lesions & P-value \\
\hline No. of lesions & $105(86.8)$ & $16(13.2)$ & - \\
Mean diameter $(\mathrm{cm})$ & 1.2 & $13(81.3) / 3(18.7)$ & 0.201 \\
Mass/Non-mass lesions & $84(80.0) / 21(20.0)$ & $2(12.5) / 14(87.5)$ & 0.999 \\
Malignant/Benign & $29(27.6) / 76(72.4)$ & 0.237 \\
\hline
\end{tabular}

Values are presented as number (\%).

US, ultrasonography; MRI, magnetic resonance imaging.

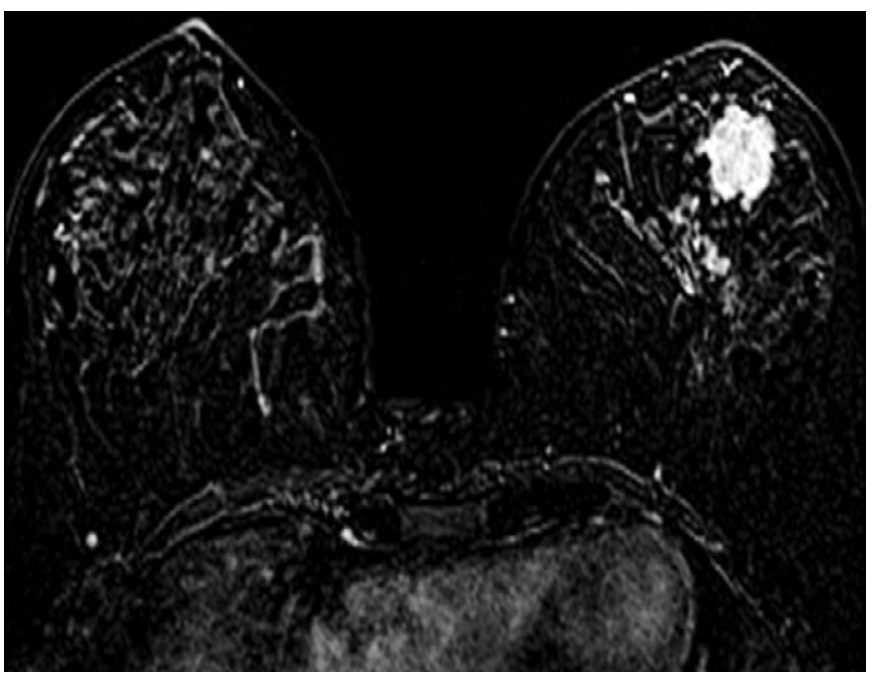

A

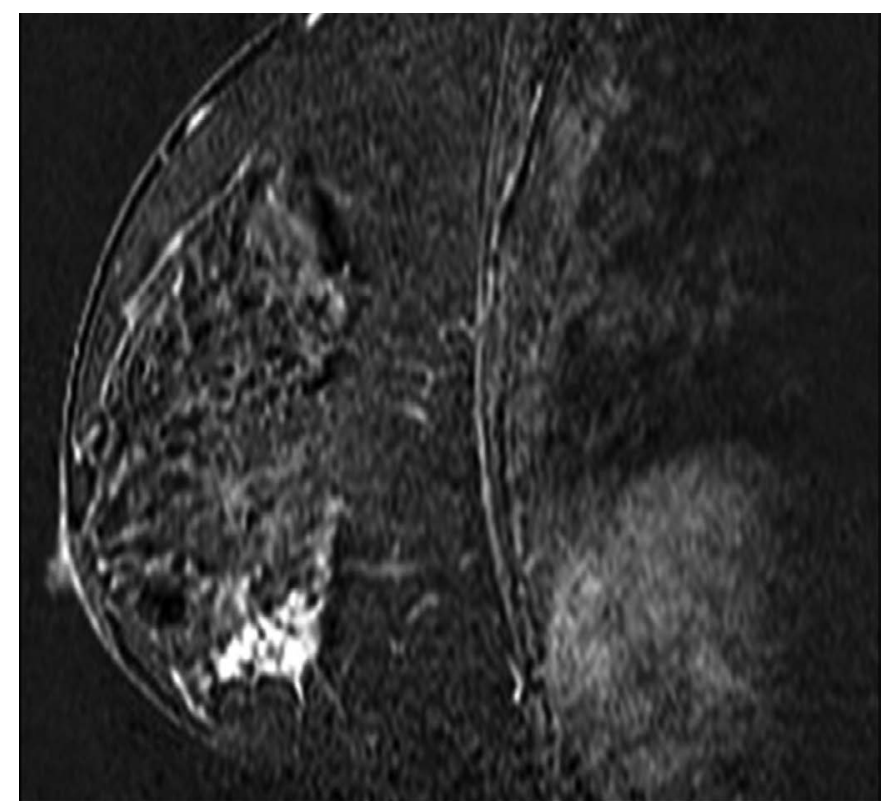

C

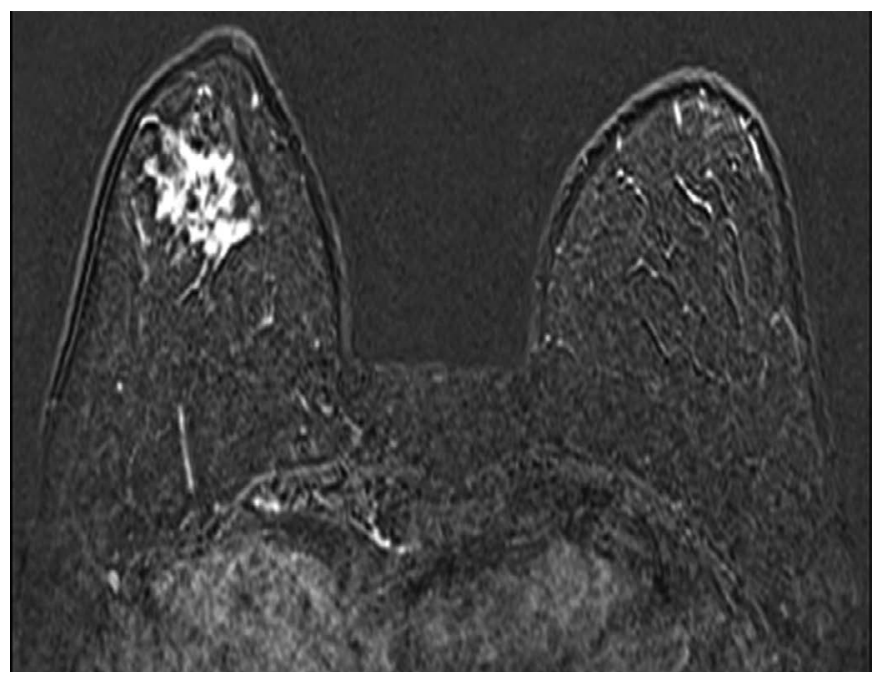

B

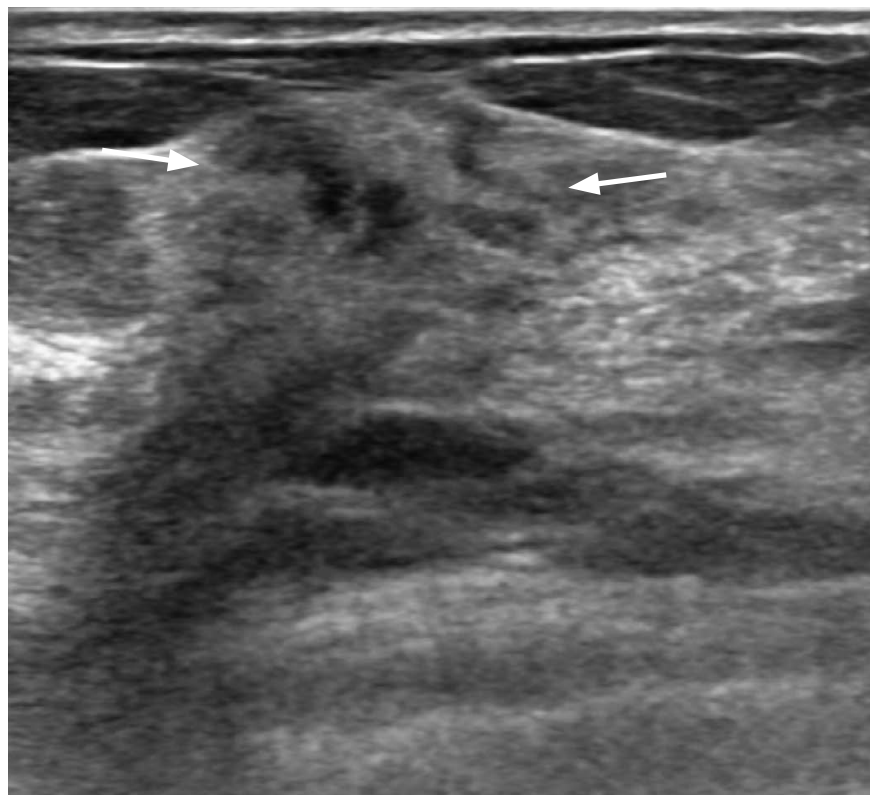

D

Fig. 1. A 46-year-old woman with cancer in her left breast.

A. A dynamic contrast-enhanced and subtracted T1-weighted axial image shows the diagnosed cancer in her left breast. B, C. A dynamic contrast-enhanced and subtracted T1-weighted image shows incidental non-mass enhancement in the lower outer quadrant of her right breast in the axial (B) and sagittal (C) planes. D. Second-look ultrasonography (US) detects a corresponding ill-defined irregular hypoechoic lesion (arrows) in her right breast. US-guided core-needle biopsy confirmed invasive ductal carcinoma in her right breast. 
seen on US. The patient's physical position should also be considered during second-look US because the breast hangs in a dependent location when the patient is in a prone position for MRI imaging. Other breast landmarks, such as subcutaneous fat, glandular tissue, and subglandular fat, are also helpful in translating information from MRI to US.

When an MRI-detected lesion was visible on US, the radiologists recorded the lesion location, that is, the clockwise direction and distance from the nipple in centimeters, according to the largest diameter in centimeters. They evaluated the lesions according to the BI-RADS lexicon [14]. The BI-RADS features were recorded beginning with whether or not the lesion was a special case, specifically defined as a cyst, complicated cyst, clustered microcysts, intraductal mass, lymph node, postsurgical scar, or calcifications. For masses, the shape, orientation, margin, boundary, echo pattern, and posterior acoustic feature were recorded. Finally, we also assessed the BI-RADS category on a five-point scale.

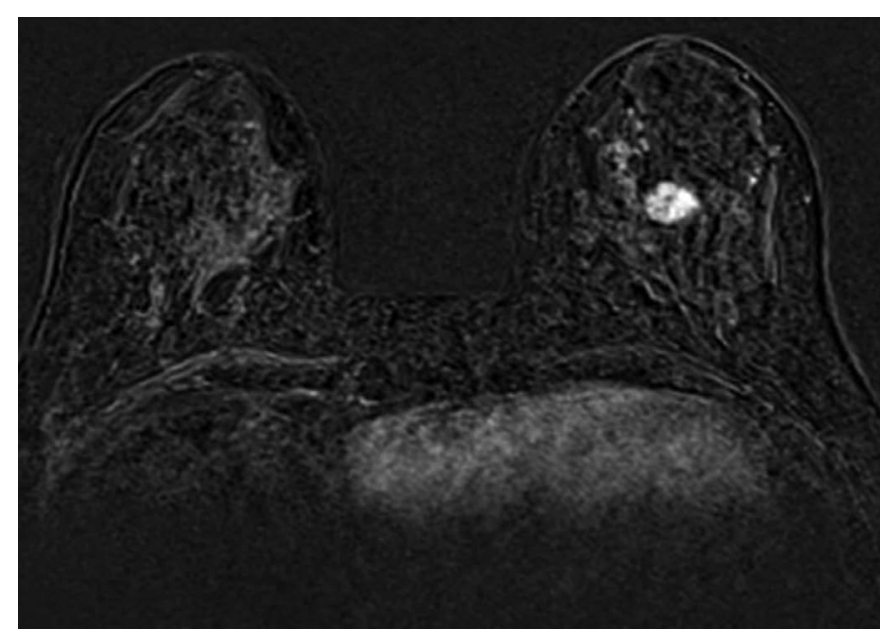

A

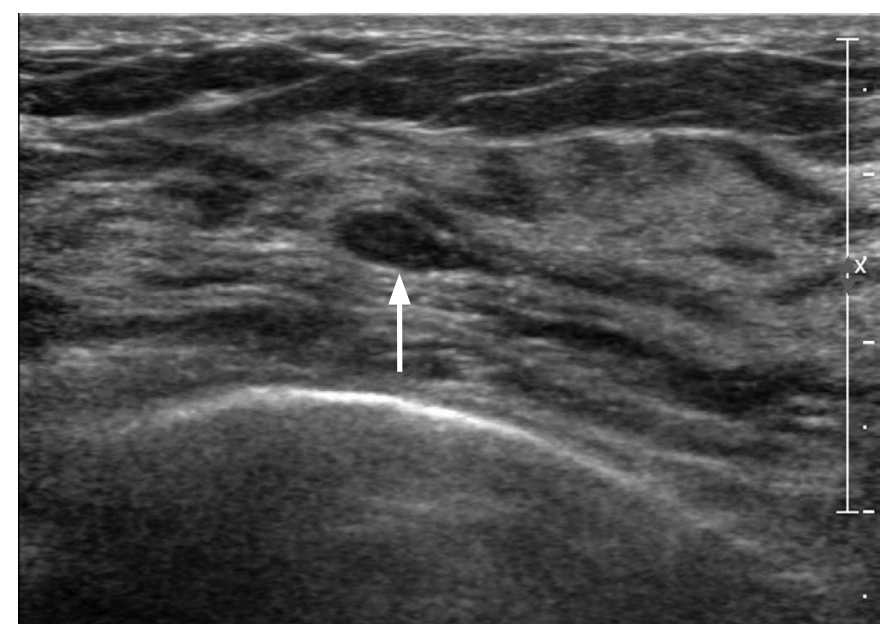

\section{Statistical Analysis}

A two-sample test and Fisher's exact test with SPSS ver. 15.0 (SPSS Inc., Chicago, IL, USA) were used for the statistical analysis. A P-value of less than 0.05 was considered statistically significant.

\section{Results}

One hundred and eight patients with 121 lesions underwent secondlook US. The mean patient age was 49 years (age range, 24 to 76 years). The lesion diameter, as seen on MRI, ranged from 0.5 to $6 \mathrm{~cm}$ (mean, $1.2 \mathrm{~cm}$ ). Of the 121 lesions, $97(80.2 \%)$ were masses and $24(19.8 \%)$ were non-mass-like lesions, as seen on MRI. The mean diameter of the masses was $0.85 \mathrm{~cm}$ (range, 0.3 to $1.8 \mathrm{~cm}$ ), and that of the non-mass-like lesions was $2.44 \mathrm{~cm}$ (range, 0.7 to $6 \mathrm{~cm}$ ).

Of the 121 lesions, 105 (86.8\%) were correlated and 16 (13.2\%) were not correlated with the findings of second-look US. The results are summarized in Table 1. The average diameter of the 105

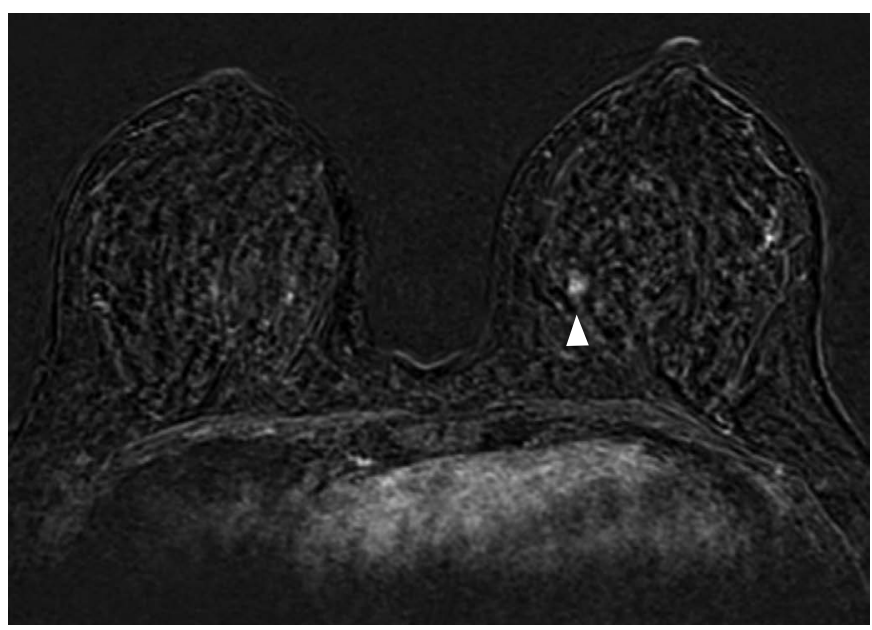

B

Fig. 2. A 52-year-old woman with cancer in her left breast.

A. A dynamic contrast-enhanced and subtracted T1-weighted axial image shows the diagnosed cancer in her left breast. B. A dynamic contrast-enhanced and subtracted T1-weighted axial image reveals another small enhancing mass (arrowhead) in her left breast. C. Second-look ultrasonography (US) detects a corresponding ovalshaped hypoechoic mass (arrow) in her left breast. US-guided needle localization and excision confirmed a fibroadenoma. 
correlated lesions, as seen on MRI, was larger $(1.2 \mathrm{~cm}$; range, 0.5 to $6 \mathrm{~cm})$ than that of the 16 uncorrelated lesions $(0.89 \mathrm{~cm}$; range, 0.6 to $2 \mathrm{~cm}$ ), although there was no statistically significant difference between the two groups $(P=0.201)$.

Of the 105 correlated lesions, $84(80.0 \%)$ were masses and $21(20.0 \%)$ were non-mass-like lesions. Of the 16 non-correlated lesions, $13(81.3 \%)$ were masses and three $(18.7 \%)$ were nonmass-like lesions. There was no statistically significant difference in the sonographic correlation between non-mass-like lesions (21 of $24,87.5 \%$ ) and masses ( 84 of $97,86.6 \%)(P=0.999)$.

All 105 correlated lesions were pathologically confirmed by means of US-guided CNB $(n=38)$ or by US-guided localization and excisional biopsy $(n=67) ; 29$ (27.6\%) were proven to be malignant, and $76(72.4 \%)$ were benign. The pathologic types of the malignant lesions included 17 invasive ductal carcinomas (Fig. 1) and 12

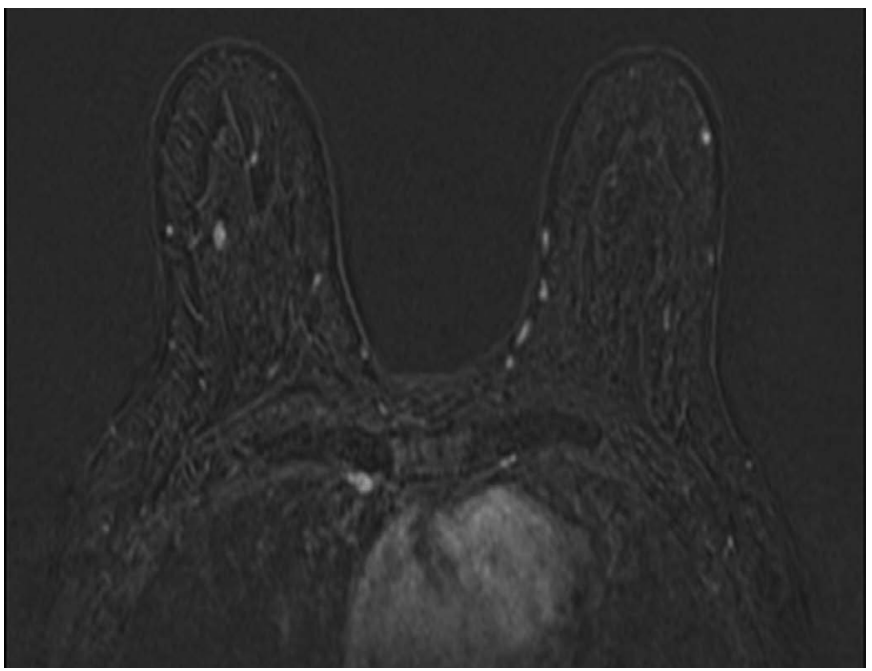

A

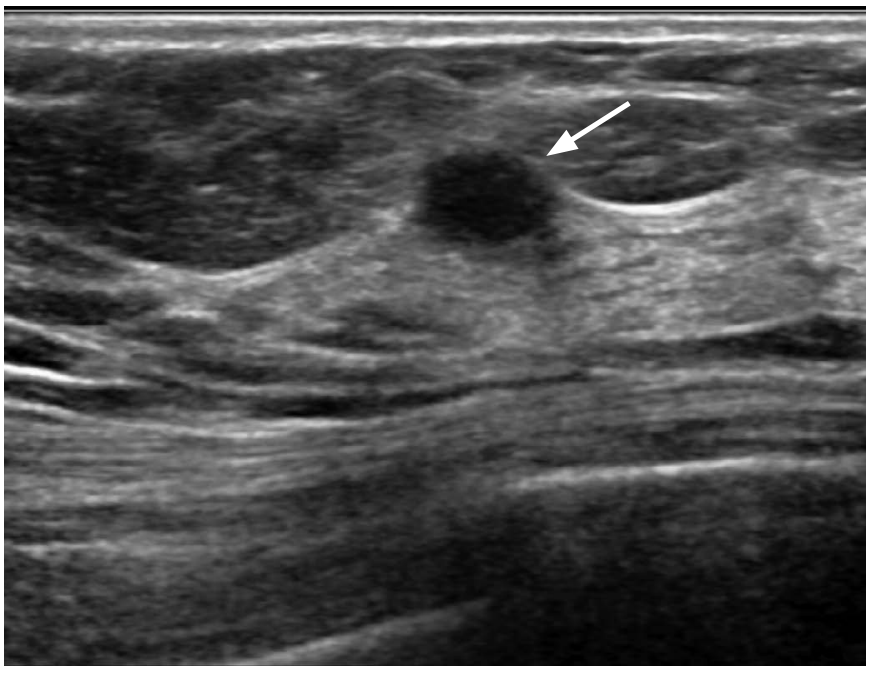

C
DCISs, and the benign lesions were fibroadenomas (Fig. 2), nonproliferative breast changes, adenosis, atypical ductal hyperplasia, usual ductal hyperplasia, dense fibrosis, columnar cell hyperplasia, fibrocystic changes, intraductal papilloma, and proliferative breast lesions. Of the 16 uncorrelated lesions seen on second-look US, two were proven to be invasive ductal cancers after a 30-month followup examination, and the patients with these two lesions underwent breast-conserving surgery (Fig. 3). The remaining 14 lesions were considered benign on the basis of a 2-year follow-up and the patients' clinical records. Although malignancy tended to be more correlated than benignancy, there was no statistically significant difference between the correlated and the non-correlated groups on the basis of the histopathology outcome as follows: benign versus malignant $(P=0.197)$ and invasive versus in-situ carcinoma $(\mathrm{P}=0.510)$.



B

Fig. 3. A 57-year-old woman with cancer in her left breast.

A. A dynamic contrast-enhanced and subtracted T1-weighted axial image shows a small enhancing mass in her right breast. There were no correlated lesions seen on second-look ultrasonography (US). B. On follow-up magnetic resonance imaging performed 30 months later, a 1.5-cm irregular, enhancing mass (arrow) is detected at the same location in her right breast. C. US shows an oval hypoechoic mass (arrow) with an indistinct margin and confirmed it as invasive ductal carcinoma. 
Table 2. Summary of second-look US studies of MRI-detected lesions

\begin{tabular}{|c|c|c|c|c|c|c|c|c|}
\hline Study & $\begin{array}{l}\text { No. of MRI } \\
\text { scans }\end{array}$ & $\begin{array}{l}\text { MRI-detected } \\
\text { additional } \\
\text { lesions }^{\text {a) }}\end{array}$ & $\begin{array}{l}\text { Lesion } \\
\text { diameter } \\
(\mathrm{cm})\end{array}$ & $\begin{array}{l}\text { Lesions } \\
\text { reviewed with } \\
\text { second-look } \\
\text { US }^{\text {a) }}\end{array}$ & $\begin{array}{l}\text { No. of lesions (\%), } \\
\text { US correlated/ } \\
\text { non-correlated }\end{array}$ & $\begin{array}{c}\text { No. of cancer } \\
\text { types (\%), US } \\
\text { correlated/non- } \\
\text { correlated }\end{array}$ & $\begin{array}{l}\text { Pathology } \\
\text { confirmed }^{\text {b) }}\end{array}$ & US correlation \\
\hline $\begin{array}{l}\text { LaTrenta et al. [10], } \\
2003\end{array}$ & 654 & $101(69)$ & 0.9 & $93(64)$ & $21(23) / 72(77)$ & $9(43) / 10(14)$ & $67(40)$ & $\begin{array}{l}\text { Cancer }>\text { Benign } \\
\text { Mass }>\text { Non-mass }\end{array}$ \\
\hline Shin et al. [16], 2007 & 149 & $69(62)$ & 1.1 & $38(31)$ & $27(71) / 11(29)$ & $15(56) / 3(27)$ & $35(0)$ & Cancer $>$ Benign \\
\hline $\begin{array}{l}\text { DeMartini et al. [20], } \\
2009\end{array}$ & 1,244 & $201(155)$ & 1.6 & $167(128)$ & $76(46) / 91(54)$ & $27(36) / 21(23)$ & All (91) & $\begin{array}{l}\text { Mass }>\text { Non-mass, Foci } \\
\text { Cancer }>\text { Benign }\end{array}$ \\
\hline $\begin{array}{l}\text { Meissnitzer et al. } \\
{[22], 2009}\end{array}$ & NA & $519(361)$ & 1.2 & $519(361)$ & $290(56) / 229(44)$ & $87(34) / 34(19)$ & $422(169)$ & $\begin{array}{l}\text { Mass }>\text { Non-mass } \\
\text { Cancer }>\text { Benign } \\
\text { Category } 5>4 \\
\text { Large size }\end{array}$ \\
\hline Abe et al. [11], 2010 & NA & $202(148)$ & NA & $202(148)$ & $115(57) / 87(43)$ & $33(29) / 11(13)$ & $115(38)$ & $\begin{array}{l}\text { Mass }>\text { Non-mass } \\
\text { Cancer }>\text { Benign } \\
\text { Invasive cancer }>\text { DCIS }\end{array}$ \\
\hline $\begin{array}{l}\text { Candelaria and } \\
\text { Fornage [18], } 2011\end{array}$ & NA & $131(83)$ & 1.0 & $131(83)$ & $88(67) / 43(33)$ & $27(31) / \mathrm{NA}$ & NA & $\begin{array}{l}\text { Foci, Mass }>\text { Non-mass } \\
\text { Cancer }>\text { Benign }\end{array}$ \\
\hline Kim et al. [17], 2012 & 853 & NA & NA & $\begin{array}{c}126(98) \\
\text { (only } \\
\text { contralateral) }\end{array}$ & $81(64) / 45(46)$ & $16(20) / 1(2)$ & $58(0)$ & $\begin{array}{l}\text { Mass }>\text { Non-mass } \\
\text { Cancer }>\text { Benign }\end{array}$ \\
\hline Present study & 1970 & 149 (135) & 1.2 & $121(108)$ & $105(86.8) / 16(13.2)$ & $29(27.6) / 2(12.5)$ & $107(0)$ & - \\
\hline
\end{tabular}

US, ultrasonography; MRI, magnetic resonance imaging; NA, not applicable; DCIS, ductal carcinoma in situ.

${ }^{a)}$ Numbers in parentheses are numbers of patients. ${ }^{\text {b) }}$ Numbers in parentheses are numbers of MRI-guided biopsied lesions.

\section{Discussion}

Breast MRI is regarded as an important diagnostic tool for the detection of breast cancer due to its high sensitivity $[1,3]$. However, its relatively low specificity requires tissue sampling to confirm the diagnosis when suspicious lesions are identified $[1,6,7,9]$. MRI is not sufficiently accurate to permit a confirmative diagnosis, and the possibility of multicentric or contralateral cancer makes a further assessment of suspicious lesions identified on MRI necessary [15]. MRI-guided biopsy is a valid next step after MRl; however, it is not widely available and is both costly and time consuming. Therefore, US-guided biopsy can be an alternative to a careful re-examination of suspicious incidental lesions found on MRI and may help patients avoid multi-step surgeries [16]. A combination of MRI and secondlook US may more effectively prevent cancers from being overlooked than the use of US alone or the use of US followed by MRI $[2,16]$.

Some previous studies have reported the utility of second-look US for suspicious, MRI-detected lesions (Table 2) $[2,5,10,11,15,17-$ 23]. However, in all of these studies, there was no defined protocol to determine which lesions should undergo second-look US versus proceeding directly to MRI-guided biopsy. Further, some studies only included lesions that were suspicious on MRI $[2,10,11,15,18,20-$ 22], whereas others included all the MRI-detected lesions, including probably benign lesions $[5,19]$. As in most of the previous studies, we excluded palpable lesions and lesions detected on mammography. We also excluded lesions seen on the initial US. We included only suspicious lesions, the identification of which might induce a significant change in patient management.

Second-look US after MRI identified $86.8 \%$ of the additional lesions seen in the patients considered in this study. This percentage is higher than that seen in previous studies reporting a $23 \%-71 \%$ detection rate (Table 2) $[10,11,16-18,20,22]$. It is well known that the efficiency of breast US is higher in the case of the small breasts of Asian women than the breasts of western women. Further, the quality of US equipment is being upgraded constantly. These facts might account for the results of the present study.

Candelaria and Fornage [18] found that a US visualization correlation was more likely when MRI-detected lesions appeared as foci $(67 \%)$ or masses $(73 \%)$ than when they appeared as non-mass lesions seen on MRI (54\%), and DeMartini et al. [20] found that a US correlation was more likely for MRI-detected lesions described as masses $(58 \%)$ than for those described as foci $(37 \%)$ or non-mass lesions (30\%). Similarly, Meissnitzer et al. [22] reported that a US correlation was more likely for masses (62\%) than for non-masses $(31 \%)$. Unlike other studies, there were no statistically significant differences in the frequency of mass detection on US based on the MRI types in the present study, although masses were slightly more frequently found with US (87.5\%) than were non-masses (86.6\%). In the present study, the mean diameter of non-masses was larger $(2.44 \mathrm{~cm})$ than that of masses $(0.85 \mathrm{~cm})$, and the number of masses 
was significantly greater $(n=97)$ than that of non-masses $(n=24)$; these factors can obviously affect the study results.

Similar to the study results of DeMartini et al. [20], LaTrenta et al. [10], and Candelaria and Fornage [18], the findings of this study revealed that the general diameter of the abnormality seen on MRI was similar to that of the lesions with and those without US correlation. In comparison, Meissnitzer et al. [22] reported that increasing the lesion diameter resulted in statistically significantly increasing the US conspicuity, with a US correlation.

Furthermore, in contrast to previous studies, in this study, malignant lesions were not more likely than benign lesions to be identified on second-look US. Candelaria and Fornage [18] reported that $70 \%$ of the benign lesions and $61 \%$ of the malignant lesions had a US correlation. DeMartini et al. [20] found a US correlation for $40.8 \%$ of the benign lesions and for $57.4 \%$ of the malignant lesions. Meissnitzer et al. [22] reported that they found $55 \%$ of the benign lesions compared with $72 \%$ of the malignant lesions. In this study, 29 of 31 malignant lesions (93.5\%) and 76 of 90 benign lesions (84.4\%) showed a US correlation. More malignant lesions showed a correlation on US than did benign lesions, although the difference was not statistically significant $(P=0.237)$. This may be influenced by the fact that there were fewer malignant lesions than benign lesions.

This study has several limitations. First, it was retrospective in design, although we enrolled only consecutive patients. Second, in this study, MRI scans were interpreted by a radiologist with 18 years of clinical experience in breast radiology; however, second-look US was performed by five other radiologists with 3-9 years of clinical experience. Nonetheless, the detection rate of second-look US was higher than that reported in previous studies. Third, we were unable to obtain pathological confirmation for non-correlated lesions as MRI-guided biopsy and localization were not available at our institution previously. In Korea, MRI-guided biopsy or localization is not generally performed, although its use is increasing these days. Therefore, the role of second-look US is important in our practice and evaluating its efficacy is vital. To the best of our knowledge, in this study, we enrolled the largest population in Asia ever studied in this field. Furthermore, as US is an operator-dependent technique, there was no assurance that all US-correlated lesions were true MRI-US correlates. However, we used a minimum of 2-year followup results as our standard of reference.

Although we found that larger and malignant lesions were more likely to be detected on second-look US than smaller and benign lesions, there were no statistically significant differences in the detection rate according to the lesion diameter or type seen on MRI or pathology. However, as second-look US identified $86.8 \%$ of the MRI-detected breast lesions in the present study, we consider it a useful diagnostic tool for lesions incidentally detected on breast MRI.

ORCID: Min Ji Hong: http://orcid.org/0000-0001-7818-4346; Joo Hee Cha: http:// orcid.org/0000-0002-1446-8195; Hak Hee Kim: http://orcid.org/0000-0002-29569212; Hee Jung Shin: http://orcid.org/0000-0002-3398-1074; Eun Young Chae: http://orcid.org/0000-0002-3478-6721; Ji Eun Shin: http://orcid.org/0000-00031173-8142; Woo Jung Choi: http://orcid.org/0000-0003-1341-6470

\section{Conflict of Interest}

No potential conflict of interest relevant to this article was reported.

\section{Acknowledgments}

This study was supported in part by the Research Fund of the Korean Society of Ultrasound in Medicine.

\section{References}

1. Orel SG, Schnall MD. MR imaging of the breast for the detection, diagnosis, and staging of breast cancer. Radiology 2001;220:1330.

2. Orel SG, Schnall MD, LiVolsi VA, Troupin RH. Suspicious breast lesions: MR imaging with radiologic-pathologic correlation. Radiology 1994;190:485-493.

3. Harms SE, Flamig DP, Hesley KL, Meiches MD, Jensen RA, Evans WP, et al. MR imaging of the breast with rotating delivery of excitation off resonance: clinical experience with pathologic correlation. Radiology 1993;187:493-501.

4. Peters NH, Borel Rinkes IH, Zuithoff NP, Mali WP, Moons KG, Peeters $\mathrm{PH}$. Meta-analysis of MR imaging in the diagnosis of breast lesions. Radiology 2008;246:116-124.

5. Brown J, Smith RC, Lee CH. Incidental enhancing lesions found on MR imaging of the breast. AJR Am J Roentgenol 2001;176:12491254.

6. Orel SG, Schnall MD, Newman RW, Powell CM, Torosian MH, Rosato EF. MR imaging-guided localization and biopsy of breast lesions: initial experience. Radiology 1994;193:97-102.

7. Morris EA, Liberman L, Dershaw DD, Kaplan JB, LaTrenta LR, Abramson AF, et al. Preoperative MR imaging-guided needle localization of breast lesions. AJR Am J Roentgenol 2002;178:12111220.

8. Heywang-Kobrunner SH, Heinig A, Schaumloffel U, Viehweg P, Buchmann J, Lampe $D$, et al. MR-guided percutaneous excisional and incisional biopsy of breast lesions. Eur Radiol 1999;9:16561665.

9. Kuhl CK, Morakkabati N, Leutner CC, Schmiedel A, Wardelmann E, Schild HH. MR imaging-guided large-core (14-gauge) needle biopsy of small lesions visible at breast MR imaging alone. Radiology 2001;220:31-39. 
10. LaTrenta LR, Menell JH, Morris EA, Abramson AF, Dershaw DD, Liberman L. Breast lesions detected with MR imaging: utility and histopathologic importance of identification with US. Radiology 2003;227:856-861.

11. Abe H, Schmidt RA, Shah RN, Shimauchi A, Kulkarni K, Sennett CA, et al. MR-directed ("Second-Look") ultrasound examination for breast lesions detected initially on MRI: MR and sonographic findings. AJR Am J Roentgenol 2010;194:370-377.

12. American College of Radiology. Breast Imaging Reporting and Data System, BI-RADS: magnetic resonance imaging. 4th ed. Reston, VA: American College of Radiology, 2003.

13. Mahoney MC, Gatsonis C, Hanna L, DeMartini WB, Lehman C. Positive predictive value of BI-RADS MR imaging. Radiology 2012;264:51-58.

14. American College of Radiology. ACR BI-RADS Breast Imaging Reporting and Data System: breast imaging atlas. 4th ed. Reston, VA: American College of Radiology, 2003.

15. Beran L, Liang W, Nims T, Paquelet J, Sickle-Santanello B. Correlation of targeted ultrasound with magnetic resonance imaging abnormalities of the breast. Am I Surg 2005;190:592-594.

16. Shin JH, Han BK, Choe YH, Ko K, Choi N. Targeted ultrasound for MR-detected lesions in breast cancer patients. Korean J Radiol 2007;8:475-483.

17. Kim TH, Kang DK, Jung YS, Kim KS, Yim H. Contralateral enhancing lesions on magnetic resonance imaging in patients with breast cancer: role of second-look sonography and imaging findings of synchronous contralateral cancer. J Ultrasound Med 2012;31:903913.

18. Candelaria R, Fornage BD. Second-look US examination of MRdetected breast lesions. J Clin Ultrasound 2011;39:115-121.

19. Carbognin G, Girardi V, Calciolari C, Brandalise A, Bonetti F, Russo $A$, et al. Utility of second-look ultrasound in the management of incidental enhancing lesions detected by breast MR imaging. Radiol Med 2010;115:1234-1245.

20. DeMartini WB, Eby PR, Peacock S, Lehman CD. Utility of targeted sonography for breast lesions that were suspicious on MRI. AJR Am J Roentgenol 2009;192:1128-1134.

21. Leung JW. Utility of second-look ultrasound in the evaluation of MRI-detected breast lesions. Semin Roentgenol 2011;46:260-274.

22. Meissnitzer M, Dershaw DD, Lee CH, Morris EA. Targeted ultrasound of the breast in women with abnormal MRI findings for whom biopsy has been recommended. AJR Am J Roentgenol 2009; 193:1025-1029.

23. Trop I, Labelle M, David J, Mayrand MH, Lalonde L. Second-look targeted studies after breast magnetic resonance imaging: practical tips to improve lesion identification. Curr Probl Diagn Radiol 2010;39:200-211. 